\title{
Now Available on Cassette-Again: Record Retailer Experiences of Current Cassette Tape Sales
}

\author{
Waleed Rashidi \\ California State University, Fullerton
}

This paper was presented at the 2019 International Summit of the Music \& Entertainment Industry Educators Association

March 21-23, 2019

https://doi.org/10.25101/19.42

\section{Abstract}

Cassette tape album sales have increased $23 \%$ in 2018 to 219,000 cassettes sold, according to a January 2019 Billboard report citing Nielsen Music figures. This continued interest in the cassette has found retailers stocking their shelves with the format, some for the first time and others after a long absence. The study provides a more current understanding of music cassette tape sales from record retailers' perspectives. This qualitative study utilizes twenty-four in-depth, semi-structured interviews with retail employees to better illustrate and comprehend reasons behind the upward trajectory in cassette sales. The insight of participants from fifteen different U.S. states ultimately generated four primary themes: customer profiles, customer preferences, sales experiences, and future sales. Findings included that cassette customers hailed from a younger demographic, playback persisted due to new product availability, cultures formed in certain locales, and most retailers were optimistic about future sales of the format.

Keywords: cassette, cassette tape, record retail, analog, cassette sales, recorded music, music industry

This project was funded by a MEIEA research grant.

\section{Introduction}

For many who grew up with the cassette tape as a primary music source, the format could be viewed as anachronistic playback technology. Some of its most important qualities - namely, its portability - were pivotal in making music listening more personal and economical, while its use as a recordable format provided the opportunity of easy audio recording. For decades, cassettes were traded, mailed, sold, and compiled (as mix tapes), but for many of its users from its heyday, such actions are largely memories of years' past. The cassette has long fallen out of favor with the general public in the United States with the more recent popularity of digital playback technologies via MP3 players, computers, and smartphones.

This is not unlike its analog video counterpart, the VHS tape, which was supplanted by the DVD, itself commonly replaced by streaming video subscription services. The last new VCR was manufactured by Funai Electric in 2016 (Rosenberg 2016). However, the audio cassette has not completely faded out, as the sale of new pre-recorded music tapes has steadily increased over the past few years in the United States. Furthermore, brand new cassette decks and portable players are still being manufactured, thus supporting (and prolonging) playback possibilities. In 2016, 129,000 units were sold, an increase of $74 \%$ from the year prior-and nearly a four-fold increase from a low point seven years earlier; in 2017, 174,000 units sold (a 35\% increase), and in 2018, 219,000 units sold, an increase of 23\% (Beach 2016; Funk 2007; Newman 2008; Brown 2010; Onsgard 2016; Olivarez-Giles 2017; Caufield 2018, 2019).

Additionally, the cassette persists as a saleable format in the used arena. The recent upward trend in sales of this audio format - popularized in the 1970s via the Sony Walkman's introduction, exceeding the sales of vinyl records by 1983 (Winters 2016) and reaching its peak in the late 1980s (Rudser 2011) —is quite notable, given the prominence, ac- 
cessibility, and omnipresence of affordable, digital devices and streaming services. Despite having been dethroned as a sales leader by the more technologically-advanced compact disc nearly three decades ago (Bair 2017), and not attaining the same desirable cachet as the recently-resurged vinyl record (Sax 2016), the cassette tape has nevertheless forged ahead, maintaining its status as yet another option for retailers of physical media, albeit sustaining only as a single-digit percentage of most stores' overall music sales. According to BuzzAngle Music's 2018 year-end report of U.S. music consumption, cassette sales were $0.2 \%$ of overall physical format music sales, at 118,700 of 74 million units, a $0.1 \%$ increase over 2017 (Lidestri 2019). The goal of this paper is to develop a more comprehensive account of how and why retailers have embraced the sale of the cassette tape in the present. Through national retail programs such as Cassette Store Day, which collectively promotes cassette tape sales via special events and releases, to the number of musicians and record labels that have opted to release new titles on cassette, the cassette tape appears to have been given a new lease on its otherwise archaic functionality, persisting as an additional analog option, in the face of rapid technological progress for consumer playback.

Some of this persistence was also aided by its exposure from visual media, namely from 2014's "Guardians of the Galaxy," of which its "Awesome Mix Vol. 1" and 2017's sequel "Awesome Mix Vol. 2" soundtracks were some of the top selling cassettes in 2018, in addition to the "Stranger Things" soundtrack, plus reissues by Britney Spears, Metallica, Elvis Presley, and the Wu-Tang Clan (Caulfield 2019). This list of reissues may not be all that surprising, given that $52.5 \%$ of 2018 's cassette sales were classified as "deep catalog" in BuzzAngle Music's year-end report of U.S. music consumption (Lidestri 2019). By conducting indepth interviews with two-dozen independent record store retailers throughout the United States, this paper aims to provide a deeper, current understanding on the state of cassette tape sales. As it stands, it appears that the cassette tape holds two distinctly different titles - a recorded music format of the past and a recorded music format for the future.

\section{Literature Review}

Despite the cassette's slow growth over the past several years, news of the cassette tape's re-emergence continues to generate fresh headlines, and their associated stories. Prominent outlets such as Popular Mechanics sported the headline "Cassette tapes are back, don't you dare call them obsolete" (Detwiler 2018) while The Guardian's "It's cool to spool again as the cassette returns on a wave of nostalgia" (Iqbal 2019) headline alludes to a possible reason for its recent popularity. The Pacific Northwest Inlander even questioned the re-emergence of the cassette tape as a re- cent source of physical music media, with its headline of "In the era of streaming music, how is it possible that cassette tapes are making a comeback?" (Weinbender 2019). In fact, Weinbender (2019) explains a reason for the cassette's re-entry into desirability - its staying power: "The tangibility is exactly what makes them special. At any time and without any advance notice, an artist's music can vanish from a streaming platform. A tape, as long as it's stored properly and treated with care, can last forever" (para. 21).

Rouner (2019) highlighted a specific scene's use of cassette tapes (headline: "Hiss and tell, Houston noise bands celebrate the cassette"), Koster's (2019) story examined the recent cassette sales revitalization (headline: "Music cassettes, once left for dead, are making a comeback"), and Leitko's (2018) story headline gives the reader permission to still embrace the cassette, even noting that it's "...the go-to format for weirdos and outsiders hoping to put out a record as anything other than ones and zeroes" (para. 2). Shuker (2016) notes the cassette's rise in format history, becoming a preferred format for developing countries and for the then-emerging punk and rap styles, both of which embraced a do-it-yourself ethos. Artists have also embraced the cassette tape, not only for its functionality as a format, but as a marker of a time period. This is evidenced by the New Kids on the Block's recent MixTape tour, which included imagery and icons of cassettes, harking back to the compilations created by consumers during the New Kids on the Block's heyday of the late 1980s (Brock 2019). An Instagram post by rapper Nas in June 2019 featured a video clip of a cracked cassette tape sculpture in promotion of his forthcoming release, The Lost Tapes II (Estiler 2019). Even athletic apparel manufacturer Nike announced a "Cassette" version of its React Presto model shoes, donning a cassette image on its insole (Dwyer 2019).

Furthering its presence in the media, the cassette was also the main subject of a documentary released in 2018 by Gravitas Ventures, titled Cassette: A Documentary Mixtape (Seven 2019). And it even became part of a storyline for acclaimed series, The Handmaid's Tale (Abdulbaki 2019). Additionally, news stories have been published about new blank cassette tapes being produced by at least two companies, Springfield, Missouri-based National Audio Company, and Avranches, France-based Recording The Masters (Mulann Industies is the parent company) (Holman 2019). It is this renewed interest in cassette tapes-from the media, consumers, retailers, and artists - that inspired the launch of this study. In an arena where streaming is dominant, vinyl has made a new impact, and CDs are less desired, what is the cassette retailing experience like in this dynamic marketplace and what is to be expected of its future? 


\section{Research Questions}

Three research questions drove the present study's line of inquiry:

- RQ1: What are the characteristics of current cassette tape customers?

- RQ2: What are current cassette tape sales experiences of record retailers?

- RQ3: What are record retailers' cassette tape sales forecasts?

\section{Methods}

This exploratory qualitative study's data were collected from 24 telephone interviews of employees at brick-andmortar record stores located across the United States. A sample size of 24 participants is considered to be acceptable for phenomenological, in-depth interviews (Creswell 2013). These semi-structured interviews averaged about 22 minutes each; the shortest was 10 minutes, 54 seconds, the longest was 35 minutes, 32 seconds. Approximately 11-14 questions were asked of each participant from a prescribed interviewer's guide. Participants were recruited from across the United States via direct email inquiries sent by the researcher. Potential participants were located from their online advertising of cassette sales; some had posts on social media accounts (Facebook and Instagram), while others had cassette sales information published on their stores' websites. Furthermore, contact information available on websites for Cassette Store Day 2018 (www.cassettestoredayusa.com) and Record Store Day 2019 (www.recordstoreday. com) featured lists of cassette retailers.

A total of 351 U.S.-based stores were contacted, with a participation rate of $6.84 \%(n=24)$. Per the institutional review board protocol, the study's participants were required to be a minimum of 18 years of age, be currently employed at a record retailer with cassette sales, and agree to the institutional review board's (IRB) informed consent document prior to the start of the interview. All interviews took place via telephone from February 2019 to June 2019. Interviews were recorded with the participant's advance consent, via a digital audio recorder. Interview recordings were subsequently transcribed, and the transcriptions were validated by the participants via member checking. Validated transcriptions were then reviewed and coded in two separate occasions, incorporating grounded theory methodology (Corbin and Strauss 1990), with a variety of themes eventually emerging from the data. These themes are presented in the following section. Participants hailed from all regions of the country, including the Western U.S. ( $n=12)$, the Midwest $(n=7)$, the South $(n=3)$, and Eastern states $(n=2)$. A total of 15 different U.S. states were represented in the participant population.

\section{Results}

Of the 24 participants interviewed, the average record store had been in business for 20.1 years. The estimated average of new and used cassette stock at these participants' stores was $24.4 \%$ new cassettes and $75.6 \%$ used cassettes; ranges varied from $1 \%$ new and $99 \%$ used cassette stock at one store, to $65 \%$ new and $35 \%$ used cassettes at another. The estimated average cassette share of the stores' overall music sales was $6.87 \%$; this range also varied substantially among retailers, with cassettes racking up $35 \%$ of a store's overall sales on the top end, to less than $0.5 \%$ on the bottom. Numbers of cassette units in stock was also highly variable among the stores that reported their figures $(n=15)$, with fewer than two dozen units on the low end, to in excess of 10,000 units (used and new combined).

While most stores stocked cassettes in some quantity and capacity from their opening day, six reported deciding to stock cassette tapes more recently, at least a few years after their business launched. The most popular music genres sold on cassette were (in order of mentions) hip-hop/rap, classic rock, metal, punk, indie rock, and blues. Other genres mentioned included (in no particular order) hardcore, alternative rock, jazz, R\&B, disco, ska, country, reggae, hard rock, noise, and soul. Most stores featured accessories related to cassette purchases, including blank cassette tapes (19 stores) and cassette players (used and/or new), either as portable Walkman-style units or cassette decks (16 stores).

Upon review of the data, several primary and secondary themes emerged (Table 1). Examining the characteristics of current cassette tape customers, the cassette customer profile theme was established to illustrate the current customers of cassette tapes. These customers were largely described as younger. With ages typically ranging from teenagers to early 30 s (some ranges were described by participants as "16-25," "18-early 30s," "15-35," and "16-30"), the demographic of cassette purchasers largely skews towards a cohort that may not have originally used cassette tapes as a playback format. Rather, some may be recently discovering

\begin{tabular}{|c|c|}
\hline Primary Theme & Secondary Themes \\
\hline 1. Cassette Customer Profiles & $\begin{array}{l}\text { Younger "Hipster" } \\
\text { Cassette Culture }\end{array}$ \\
\hline 2. Cassette Customer Preferences & $\begin{array}{l}\text { Tangibility } \\
\text { Value Pricing }\end{array}$ \\
\hline 3. Cassette Sales Experiences & $\begin{array}{l}\text { Social Media } \\
\text { Theft Consideration } \\
\text { Sales Floor Reconfiguration } \\
\text { Playback Persistence } \\
\text { Cassette Accessories }\end{array}$ \\
\hline 4. Future Cassette Sales & $\begin{array}{l}\text { Optimistic Outlook } \\
\text { Pessimistic Outlook }\end{array}$ \\
\hline
\end{tabular}

Table 1. Themes from responses. 
it for the first time. One retailer shared, "Our cassette customers are, I would say on average, are going to be a younger DIY kid." Another retailer stated, "The people buying the used tapes are definitely younger...There's a generational transfer going on...People bringing them in [to sell to the store] are like over fifty, and the people that are buying them [from the store] are under thirty." This other response was linked to vinyl's recent rise in popularity: "The only thing I am seeing is that, yes, younger people are buying cassettes right now, and I saw that right when the crest of LPs started to gather steam."

In addition to - or sometimes in concert with-the younger description, retailers also used the term hipster, another subcategory of the cassette customer profile, to describe their typical cassette customers. The definition of a hipster is difficult to detail, as it can wildly vary as a subjective descriptor and could be regionally specific, or genre specific. Nevertheless, the term was used by several retailers in their descriptions of cassette customers, as evidenced here: "It's kind of hipster. That may be the one culture that, I can say that the bulk of the cassette customers are hipsters. And I can't say that about the other formats in my store..." Another retailer noted, "For cassettes...you get hipsters. They're coming in. They're twenty years old. They're all hipstered out and buying cassettes." And the hipster term was implemented in another participant's description, stating, "They definitely are kids that are going to be kind of ahead of the curve on what's cool."

Other retailers offered non-specific demographics; from their perspectives, there was no dominant cassette customer profile, but rather a variety of customers interested in tapes. "It's like there's no single age or race or gender that I can narrow it down by. It really is kind of a wide mix of people who asks about them," said one participant. Another said, "So it doesn't seem to be skewed to any particular, you know, age demographic, as far as I can tell." Echoing the earlier responses was this retailer: "It isn't specifically one demo of consumer, it's four or five."

Some participants noted that there was still a market for tapes for customers in their $40 \mathrm{~s}, 50 \mathrm{~s}$, and $60 \mathrm{~s}$ - age brackets more likely to have originally interacted with cassettes in their youth. One retailer stated that a reason for the older age brackets' interest may stem from their playback options; chiefly, their vehicles are still equipped with cassette players, making it an appealing option: "Well, there are a few people in their 50s and 60s that still have their old players or maybe even still have a car that has a player in it that might be buying cassette tapes that they remember from their younger days or bands that they remember from their younger days and kind of revisiting that."

A third subcategory of the cassette customer profile theme is the existence of a cassette culture near the retailer's locale and what such culture entailed. While some retailers felt an absence of a cassette culture in their vicinity, many said a cassette culture - of some kind - existed. Nevertheless, defining cassette culture proved difficult, given the range of responses. One retailer, who disassociated the cassette from cassette culture, said, "I think the culture comes from just the kids wanting to be analog...I think it's all about the analog, and not about the format." Analog was the theme of another retailer's opinion on cassette culture, as evidenced here: "I would say it's people that find the analog sound of the cassette tape superior to the $\mathrm{CD}$, and the ease of being able to duplicate your recordings in the privacy of your home and disseminate them fairly affordably."

This participant felt that cassette culture variance was dependent on its associated genre. "Every niche, there's a little bit of everything for everyone. I think cassette culture's very much one of those things. You know, obviously, there are genre attachments. If it's DIY, lo-fi scene, that totally makes sense. If it's hip-hop scene, [it's] sort of reverence to ' 80 s culture, that kind of sense. Which I think are two entirely different things." Another retailer also segmented the cassette culture concept, stating that "it's probably maybe a couple different subcultures. I think that there's the nostalgia crew. There's the kids that just have the crummy cars and that's kind of a whole different segment of those." The cassette culture concept was also parsed by a different retailer, who described it as "insular and isolated" by genre:

I think just also the buying of prerecorded music on cassettes and then also buying blank [cassettes], and making mix tapes, and putting your band stuff on there, and that sort of thing - I think that there's two distinct cultures there, but they definitely overlap in terms of a lot of bands who are putting their music on cassette that might be smaller bands, local bands who can't afford to press on CD or press on vinyl yet...It tends to be hip-hop culture, punk rock culture, and then the indie rock landscape, are the three that we see doing that, and as a result, their clientele we see buying the new tapes, at least.

But cassette culture was a bit more defined in other instances, including this retailer's response, in which a local high school had fostered its own culture through one of its student organizations:

I've definitely had young people come in here that are part of a cassette club at their high school. Just blows my mind. What they do is make mix tapes. That's why sometimes they want a cassette player that is a dual cassette player, so they can make copies. They'll put music, or buy cassette tapes, 
or make their own kind of cassette tapes and pass them around to the members of the club.

In terms of customer preference for cassettes, many retailers noted that customers were inclined to use cassettes for their tangibility. This may be due to a desire to interact with a physical music format as opposed to digital files and streams. "They want that tactile sense of playing the music from something other than just pushing a button on a screen and calling up whatever they want," said one participant. Another retailer found that the genres available on cassette attract audiences that would prefer to collect a physical product:

I think the audiences who support those genres tend to be collectors. They tend to want to collect maybe everything that a label, or an artist, or a band that they admire put out, which therefore, means $\mathrm{CD}$, cassette, and LP. Also, I think in some of those genres too, for instance, with punk rock stuff, the cassettes, for the most part are a cheaper format. It still allows the audience to get into the music in a physical, tactile fashion and be buying something that's affordable, which would be the cassettes.

As stated in the above quote, another customer preference for cassettes was affordability in its value pricing. Since cassettes are often less expensive than their vinyl or compact disc counterparts, they are an enticing offering to customers. Many retailers noted that their used cassettes were priced between one and five dollars, and that new cassettes ranged from five to fifteen dollars; this pricing was usually lower than a comparable vinyl LP record and, for some titles, the compact disc. This retailer said, "I think maybe... having a title people are familiar with, with the price range of a cassette, is probably the biggest factor." Another retailer compared its pricing to a vinyl record, stating, "I think part of it is that some of these kids, too, are just like, 'I'm not gonna pay $\$ 25$ for an LP, I'm buying cassettes." A third retailer echoed this sentiment, also making a comparison to other formats: "Our main cassette tape buyers are just... looking for those full albums in a lower price range. It's kind of an easy thing to get exposed to a full album at a fraction of the cost of a CD or LP."

However, retailers noted that many independent and self-funded artists also preferred the value pricing of cassette replication as an economical entry point. The ability to mass produce cassettes at a lower price point than vinyl records or compact discs has made the cassette desirable for artists with limited funds for pressing recordings. Said one retailer, "I think they're a great [format]...especially for bands that are starting out or local bands. It's an easy thing for newer bands to take on tour [and]...not as big of an in- vestment for customers. They've become an easy way to introduce newer music to an audience...that might stay away from streaming...It's just a lower risk for the bands and the customers." And this comment by a third participant also reinforced value pricing via a lower entry point for funding an album on cassette: "And for a small band that nobody knows yet? One, they don't have any money. Two, it's so hard to move 300 LPs. And three, it's just...the cost. And as a small band, you can make your own tapes, you can have a limited run. You can go on a little week tour... We have an album, let's put it out on cassette, make 50, 75 of them. And then, boom, done, that's it."

In terms of current cassette tape sales experiences of record retailers, some have engaged in social media posts to generate awareness of the fact that they stock cassette tapes in their stores. However, most participants said they do not promote the sale of cassettes much differently than they would for the other available formats for sale. Regarding cassettes, this retailer stated, "If I get 'em, I put 'em on Instagram and link it to the Facebook page. Otherwise, I don't really do much promotion at all here." Another retailer also used Facebook and Instagram for social media posts about cassettes, saying, "My main way of marketing stuff is Instagram or Facebook. I do a lot less of it with the cassettes, but if I get a cool stack of old vintage cassettes in, I'll pop a video or a photo up just like I would for the used vinyl or the new vinyl."

Two more subcategories of the sales experience theme emerged, discussing ways in which stores have configured their sales floor to accommodate the merchandising of cassette tapes. The first is theft consideration, as cassettes are physically smaller than $\mathrm{CD}$ and vinyl formats. One retailer said they hadn't knowingly experienced cassette theft but knew of other stores who have: "It's a lot easier to grab a cassette and put it in your pocket without me seeing, than an album. The newfound resurgence brings some negatives too." Another retailer had to revert to their former system of cassette sales, due to the increase in popularity, in an effort to avoid theft: "We're moving back toward that system again where some of the more desirable ones, we don't feel like we can leave them in the case, and so we have a filing system where we have the tapes behind the register and then just the empty case with the paperwork where the customers shop that."

The next subcategory is sales floor reconfiguration. Due to the influx of additional cassettes for sale, some stores had to accommodate this format for the first time, whereas others had to expand their existing shelving and display cases. (Note: Some stores did not report much reconfiguration at all; their setup was either easily expanded upon or did not require any change.) Just under half of the stores reported making changes to their sales floors to accommodate recent 
cassette sales. For example, this participant was inspired by the record retail chain Tower Records' display methods: "Now I've mimicked the Tower Records racks that I remember and all the cassettes are in those kinds of things now. So now they're on a wall rack, it's about six feet high." Another participant spoke about finding a specific type of display cases, Napa Valley cassette storage units, to aid in the expansion of their store's cassette inventory:

I started to actively look for those, which are also quite expensive now and create walls where I could put the cassettes up there. That was kind of the only way to show them. Even now, it's overflowing to the ground onto the counters. It's all over the place, it's a lot of cassettes...All the time, I'm looking for more of these Napa Valley or its equivalent cassette storage units. And, for whatever reason, I mean you could pick these up for five bucks if you wanted them [prior to now]. And now like $\$ 60, \$ 100$, for just a wooden storage unit...It's amazing to me why they got so expensive, but I think it's tagging along with the cassettes. People will now want a place to display them. There's not enough to go around now.

An additional subcategory of the sales experience theme is playback persistence, of which retailers revealed the ways customers continue to play their cassettes. The retailer may also enable the customer to continue playing cassettes through the sale of accessories, such as portable players, cassette decks, head cleaner, and blank cassettes. Several retailers spoke of the continued use of automobile cassette players as a reason why cassettes continue to sell in their stores. One retailer said, "The other story I hear the most is...'My mom gave me their old car and it's got a cassette deck in it,' and they're a poor kid and they can't afford to upgrade the stereo system so it's easier to come buy cassettes rather than redo a [car's] stereo system." A similar account came from another retailer: "I hear kids also saying sometimes some of the vehicles that have been passed down to them still have cassette players, so they're eager to come in and buy cassettes for their cars. I heard that a few times expressed in the shop." A different retailer also provided an identical observation: "I would say all of them, the majority of them are probably under thirty. It's usually just based on need. Like they get a second-hand car and it comes with a cassette player in it, and that's their only source of music for the car so that's what they go with."

However, it is not just teenagers or younger adults who are purchasing cassettes for playback in their cars. This participant noted that middle-aged customers are also making purchases for similar reasons: "Maybe, like 30s to 40s or maybe even to $50 \mathrm{~s}$, where people are getting them. Like, 'I remember this tape,' or, 'I was looking for this tape,' or, 'I want this tape for my car or truck.'” Interestingly, this retailer had a specific theory as to the longevity of the cassette player's functionality in cars, in particular, finding that the reliability and stout engineering of Japanese components has kept such players viable, two or three decades after their manufacture:

And one of the reasons is...the legacy of [the] ' $80 \mathrm{~s}$ and '90s Japanese audio engineer...And of course it's all the $\$ 1,500$ cars. So when you're an 18-yearold kid, how in God's name else are you going to encounter the technology? What, 'cause your grandpa has a Nakamichi in his living room, or something? The only way these kids are ever gonna see a tape deck is in these cars. And these cars are still on the road. So it is a direct legacy of ' 80 s, '90s Japanese audio engineering that you have all these kids that actually have access to a cassette player.

A second example of playback persistence is the sale of cassette accessories by these retailers, enabling the user to play cassettes, or enhancing the customer's current cassette use experience. As mentioned earlier, 19 of the 24 stores $(79.2 \%)$ interviewed sold blank cassette tapes and 16 stores $(66.7 \%)$ sold used and/or new cassette players or recorders, in portable or stereo component forms. This retailer offers differing lengths of blank cassettes for particular types of recording: "Yeah, we have a bunch of blank tapes, I keep a bunch of short tapes around for people to use for fourtrack projects, we have boomboxes, we have refurbished tape decks... We have two guys in town that fix tape decks for us."

Another participant spoke of how blank cassette tapes were sparsely available in their locale. "We do actually have quite a few original blank tapes that people come in and buy. And I guess they're not really easy to find in this area...We have quite a few that we still have in storage." The sporadic nature of blank tape availability was echoed by this participant, who was located in a completely different region of the United States: "Blank tapes we used to, we used to carry them and we certainly will whenever we can find them...We used to have about [400] or 500 here. And now we have absolutely zero. They [go] really quick, but we like to make everything cheap."

Providing customers the technology to play their cassette tapes was common in many stores' responses, adding to the subcategory of playback persistence. Types of cassette players sold by retailers ranged from inexpensive, simplistic portable units, to higher-fidelity, component stereo recording decks. "We do sell cassette players from time to time," said one retailer. "Right now, the only ones we have are like 
the Jensen 'Walkmans' that we purchase brand new. However we do refurbish, buy, and sell cassette players whenever we can find them in working order." Another participant, who sold cassette decks, said they have been popular sellers at their store: "Well, we do have decks...In the beginning, cassette decks would come in and I'd pass, no one cares about cassette tapes. Now, I've been picking those up when I can. Recently, the biggest seller I've had has been cassette decks. I haven't sold a record player or a receiver in a little bit, but cassette decks, I sold like four in the last month. That's kind of blowing up."

The future cassette sales theme arose from record retailers forecasting the future existence and retail viability of the cassette tape. Approximately $63 \%$ of the retailers interviewed reported what could be characterized as an optimistic outlook. Some of these responses include, "Oh, I think they'll sell as long as I get 'em, as long as the guys are still making 'em," "I would say at least [for] the next ten, fifteen years. I don't see them going away anytime soon," and, "I think there is an opportunity with cassette and I've had numerous conversations with label representatives that they should be considering reissuing catalog titles... on cassette." This retailer believes that cassettes will maintain a position in the marketplace due to the increasing prices of vinyl:

I think as long as the prices on vinyl keep going up, then cassettes are definitely going to be a thing... Yeah, I mean vinyl is at an all-time high and it's almost embarrassing, the prices that some people are trying to charge for records...So if I was a person with limited means, I would definitely be going for the cassettes.

However, not all found the cassette tape likely to persist in sales at their stores. About $37 \%$ of retailers interviewed reported what was interpreted as a pessimistic outlook on future cassette sales. Some of these responses included: "Yeah, it's definitely declining. I think that was just a oneoff fluke. I don't think it'll go away completely, but I think it'll go away for the most part...I don't think they're going to last," and, "Comparatively, I have more faith in LPs sticking around than I do cassettes. Maybe even CDs."

This participant felt that cassettes will become over-commercialized, possibly to the point of extinction: "My feelings are that big business destroys everything and they're gonna take something that, again, started from the streets, just like hip-hop, or punk rock, or doo-wop, and they're going to monetize it and take advantage and exploit it until it's dead." Another participant offered similar sentiments of a record label pricing a cassette above its physical format counterpart:

Proceedings of the 2019 International Summit
One weird thing I've seen happen now too, this happened...I can't remember when... where the label was putting out the LP, CD, and cassette, and the [cassette's] cost and the list price was actually higher than the $\mathrm{CD}$ cost and list price. That's the first time I've seen that and was kind of taken back by that in thinking like, "Wow, that's crazy that a new cassette now is coming out and it's costing more than a new CD." When I see that also it puts up warning signs, feeling like...there's a major label I believe, that if you're doing that, then you're negating part of the reason of why the cassettes are selling.

\section{Discussion}

In an era which digitally-streamed music technologies playable on a multitude of portable devices are being adopted at a rapid pace by the listening public, the rise in cassette sales further emphasizes that physical music, even on a format once deemed obsolete by many, still has its place in some listeners' media spheres. In response to RQ1 (What are the characteristics of current cassette tape customers?), numerous retailers' profiles of primarily younger customers may offer longevity for the format, as some of these customers may only recently be finding their way into the physical music media realm. Launching or further establishing their collections, coupled with the excitement of tangible discovery as they peruse brick-and-mortar stores, such younger customers appear to be the driving force via their interest in yesteryear's technology. This parallels Weinbender's (2019) article on the actual ownership of physical music, and the cassette's attraction. However, cassettes also fulfill the role of affordability and usefulness as a format for older adults, whose playback mechanisms - specifically in their automobiles - may not accommodate other formats. In addition, cassettes seem to provide nostalgia across segments, in the many reissues of largely classic artists from decades earlier. The materialization of a cassette culture, however loosely defined it may be by the various retailers, may also sustain a sales drive for the format. Maintaining this community of like-minded format connoisseurs could be necessary to ensure interest remains stimulated; the onus of said maintenance may rest on the shoulders of the retailers.

While cassette tapes are still a slim fraction of most retailers' overall sales, some have embraced the "return" of the format. One unique element in response to RQ2 (What are current cassette tape sales experiences of record retailers?) was how certain retailers had to rethink their cassette displays. Such aforementioned reversion to setups used decades earlier found retailers turning to the past to revise their store for future sales. Perhaps much to the fortune of these customers' preferences for an older format, the man- 
ufacturers have continued to produce new players, blank cassettes and maintenance items, which have in turn enabled retailers to sell such accessories, better ensuring the format's longevity.

Overall, the outlook on cassettes seems to be one of positivity (RQ3: What are the cassette tape sales forecasts by record retailers?) and hopefulness. Retailers may be inclined to endorse any format that finds revived favor, as it is their stock-in-trade. But, the aforementioned reported statistics buoy this sentiment, with increased sales pointing towards a rosy future, as consumers seek interaction with their music and opportunities to engage with listening experiences in the analog domain. With some stores building their used and new stock, as labels add more cassette titles to their catalogs, and independent artists turn to the cassette as an economical means of tangible music distribution, this might not be a misplaced outlook. After all, the cassette has its merits, that other physical, analog audio formats may not share: vinyl is not as portable, 8-track players are arguably more archaic, and reel-to-reel recorders are more complicated to operate. Noting its advantages in 1992's Cassette Mythos, McGee wrote, "The audio cassette is the perfect vehicle: inexpensive, portable, and malleable" (p. vii).

Still, for some retailers, the boom is over, and the industry has already reached "peak cassette." For them, the possibility of the cassette tape returning as a true analog companion to vinyl records never materialized, amid less-than-promising sales. If the format remains in their stores, it may only be viewed as a niche product. Such positions could be due to the genre(s) of music which the retailer focuses on, or even the area in which they are based.

\section{Limitations and Future Research}

This study was largely limited by its geographic scope. By only conducting interviews with United States-based retailers, it does not make any attempt to paint a wider, more vivid international image of cassette sales, and thus could mostly be applicable within its domestic boundaries. Studies of other countries' engagement and sales of cassette tapes would elucidate the phenomenon on a much grander scale than a sampling of U.S.-based retailers. Other countries could embrace or eschew physical music formats in ways that may parallel or run counter to U.S. trends. These comparisons would be of great interest.

A study of why music artists engage in the current production and sale of cassettes could incorporate several genres and highlight both the commonalities and divisions of these genres, or it could be a case study focusing on a particular genre and its specific interaction with cassette tapes. Additionally, a study of how and why record labels engage in cassette marketing and sales could bolster such discussion. Because some of the retailers had mentioned that the cas- sette sales demographics sometimes reached beyond that of the young adult, studying older audience segments (e.g., Generation X or Baby Boomers) could be of value in understanding their usage experiences of cassettes, and how this may influence the current physical music marketplace.

The study also generated an interesting tangent of the current sales of other analog formats such as VHS videocassettes, reel-to-reel, and 8-track tapes. Five retailers reported current sales of VHS tapes, while seven stores reported they either currently sold reel-to-reel tapes (with some even selling reel-to-reel recording units) or had sold them in the past and would sell them again if they acquired more. And ten retailers reported sales of the 8-track cartridge, another analog tape-based format, likely thought as obsolete by most music audiences. One of the reasons given for 8-track purchases was that owners of classic cars may still have 8-track players in them. The reel-to-reel and 8-track formats could also spark additional interest from younger audiences already inclined to use the cassette. 


\section{References}

Abdulbaki, Mae. "How Those Cassette Tapes May Prove Useful in 'The Handmaid's Tale' Season 3." Inverse, June 20, 2019. https://www.inverse.com/article/56917handmaid-s-tale-season-3-spoilers-cassette-tapes-junemark-tuello.

Bair, Jessica. "Tale of Cassette Tape Winds Down." Central Penn Business Journal 23, Issue 50 (December 7, 2007). https://search.proquest.com/ docview/236260127?ac-countid=9840.

Beach, Randall. "Cassette Tapes Hold Fond Memories, Romance for Baby Boomer." New Haven Register, May 18, 2010. https://www.nhregister.com/news/ article/Cassette-tapes-hold-fond-memories-romancefor-11593622.php.

Brock, Amanda. "New Kids on the Block's MixTape Tour Brings New Twist to Old School Hits." Nerds and Beyond, June 23, 2019. https://www.nerdsandbeyond. com/2019/06/23/new-kids-on-the-blocks-mixtapetour-brings-a-modern-twist-to-old-school-hits/.

Brown, August. "Let's Go to the Tape." Orlando Sentinel, August 10, 2010. https://search.proquest.com/ docview/744358801? accountid=9840.

Caulfield, Keith. "U.S. Cassette Album Sales Grew 23\% in 2018, Aided by Britney Spears, 'Guardians,' Twenty One Pilots \& More." Billboard, January 17, 2019. https://www.billboard.com/articles/columns/chartbeat/8493927/us-cassette-album-sales-2018-britneyspears-guardians-twenty-one-pilots.

Caulfield, Keith. "U.S. Cassette Album Sales Increased by $74 \%$ in 2016, Led by 'Guardians' Soundtrack." Billboard, January 20, 2017. https://www.billboard. com/articles/columns/chart-beat/7662572/us-cassettealbum-sales-increase-2016-guardians.

Caulfield, Keith. "U.S. Cassette Album Sales Rose 35\% in 2017, Led by 'Guardians of the Galaxy' Awesome Mix Tapes.” Billboard, January 5, 2018. https://www. billboard.com/articles/columns/chart-beat/8092853/ cassette-album-sales-rising-2017.

Corbin, Juliet M., and Anselm Strauss. "Grounded Theory Research: Procedures, Canons, and Evaluative Criteria." Qualitative Sociology 13, no. 1 (1990): 3-21. https://doi.org/10.1007/BF00988593.

Creswell, John W. Qualitative Inquiry and Research Design: Choosing Among Five Approaches. Thousand Oaks, California: Sage, 2013.

Detwiler, Jacqueline. "Cassette Tapes are Back, Don't You Dare Call Them Obsolete." Popular Mechanics, November 12, 2018. https://www.popularmechanics. com/technology/audio/a24848370/cassette-tapes-national-audio-company/.
Dwyer, Ross. "The Nike React Presto 'Cassette' is Arriving Soon.” Sneaker News, May 30, 2019. https:// sneakernews.com/2019/05/30/nike-react-presto-cassette-av2605-101-release-info/.

Estiler, Keith. "Nas Confirms 'The Lost Tapes II' Album Release." Hypebeast. June 11, 2019. https://hypebeast. com/2019/6/nas-the-lost-tapes-ii-album-daniel-arsham-future-relic-cassette.

Funk, Josh. "Cassette for Life? Tapes Still Relevant." Journal-Gazette. August 14, 2007. https://search.proquest.com/docview/411433141 ?accountid=9840.

Holman, Gregory J. "National Audio Company Now Has a Cassette-Making Competitor. They're in France." April 22, 2019, Springfield News-Leader. https://www. news-leader.com/story/news/local/ozarks/2019/04/22/ springfield-audiocassettes-business-national-audio-company-cassette-making/3501329002/.

Iqbal, Nosheen. "It's Cool to Spool Again as the Cassette Returns On a Wave of Nostalgia." The Guardian, February 23, 2019. https://www.theguardian.com/ music/2019/feb/23/cassette-tape-music-revival-retro-chic-rewind.

Koster, Rick. "Music Cassettes, Once Left for Dead, Are Making a Comeback." The Day, March 5, 2019. https://www.theday.com/article/20190305/ ENT10/190309718.

Leitko, Aaron. "It's Okay to Still Love Cassettes and You Can Show Your Affection on Saturday." Washingtonian, October 12, 2018. https://www.washingtonian. com/2018/10/12/its-okay-to-still-love-cassettes-andyou-can-show-your-affection-on-saturday/.

Lidestri, Jim. "BuzzAngle Music 2018 Year-End Report: U.S. Music Industry Consumption.” January 8, 2019. https://www.buzzanglemusic.com/wp-content/uploads/ BuzzAngle-Music-2018-US-Report-Industry.pdf.

McGee, Hal. "Forward." In Cassette Mythos, edited by Rob James, Dave Mandl, and Neil Strauss, vii-viii. Brooklyn, New York: Autonomedia, 1992.

Newman, Andrew Adam. "Say So Long to an Old Companion: Cassette Tapes." New York Times, July 28, 2008. https://www.nytimes.com/2008/07/28/business/ media/28cassette.html.

Olivarez-Giles, Nathan. “Can't Stop the Music: The Cassette Tape May Have Been Given the Heave-Ho Long Ago, but the Format's Nostalgic Appeal is on a Comeback Tour." Wall Street Journal, March 11, 2017. https://search.proquest.com/docview/1875989655?accountid $=9840$.

Onsgard, Kristen. "Cassette Tapes are Trendy Today, But Always Cool." The DePaulia, October 17, 2015. https://depauliaonline.com/16459/artslife/cassettetape-trend/. 
Rosenberg, Gabriel. "So Long, VCR. We Hardly Knew You (Were Still Around)." NPR-All Tech Considered, July 21, 2016. https://www.npr.org/sections/alltechconsidered/2016/07/21/486889433/so-long-vcr-we-hardlyknew-you-were-still-around.

Rouner, Jef. "Hiss and Tell, Houston Noise Bands Celebrate the Cassette." Houston Chronicle, March 1, 2019. https://www.houstonchronicle.com/entertainment/music/article/Hiss-and-tell-Houston-noise-bandscelebrate-the-13652558.php.

Rudser, Lauren. "Miss the Hiss? Fanatics Flip for Tunes on Cassette Tapes - Album Connoisseurs Eschew the Shuffle, Embrace Flaws; That 'Sweet Plasticy Smell.", Wall Street Journal, October 20, 2011. https://www. wsj.com/articles/SB1000142405297020400230457663 1361693349974.

Sax, David. The Revenge of Analog. New York, New York: PublicAffairs, 2016.

Seven, John. "Viewer's Discretion: Film Celebrates the Cassette Tape, Mixtapes." The Berkshire Eagle, February 8,2019 . https://www.berkshireeagle.com/stories/ john-seven-viewers-discretion-film-celebrates-the-cassette-tape-mixtapes, 564299.

Shuker, Roy. Understanding Popular Music Culture. 5th ed. New York, New York: Routledge, 2016.

Weinbender, Nathan. "In the Era of Streaming Music, How is it Possible that Cassette Tapes are Making a Comeback?" Inlander, Feb. 21, 2019. https://www.inlander. com/spokane/in-the-era-of-streaming-music-how-is-itpossible-that-cassette-tapes-are-making-a-comeback/ Content?oid $=16590570$.

Winters, Paul E. Vinyl Records and Analog Culture in the Digital Age. Lanham, Maryland: Lexington Books, 2016.
Waleed Rashidi is an assistant professor in the Department of Communications at California State University, Fullerton, and also serves as advisor to the Entertainment and Tourism Club and Comm Week. Rashidi has worked as an editor covering music at Mean Street Magazine and the Inland Empire

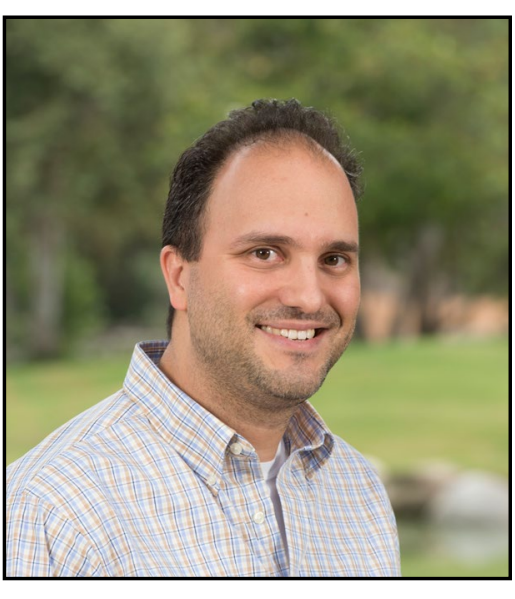
Weekly. He hosts a weekly jazz radio show at KSPC 88.7 FM since 1997, contributed to five books, and has freelanced for the Los Angeles Times-Brand X, Alternative Press, Orange County Register, Modern Drummer, E! Online, and $O C$ Weekly. Rashidi earned his doctorate in education from the University of La Verne, an MA in communications from California State University, Fullerton, and a BS in communication-journalism from Cal Poly Pomona. 


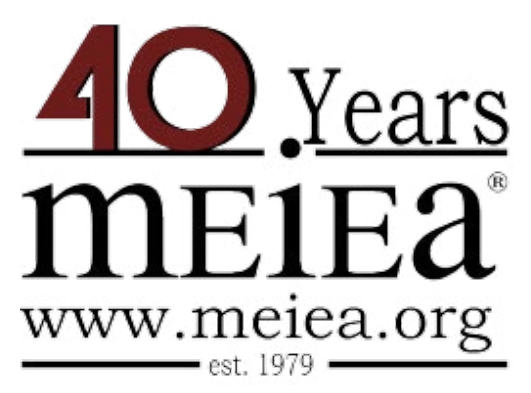

\section{PROCEEDINGS OF THE \\ 2019 INTERNATIONAL SUMMIT \\ OF THE \\ MUSIC \& ENTERTAINMENT \\ INDUSTRY EDUCATORS \\ ASSOCIATION}

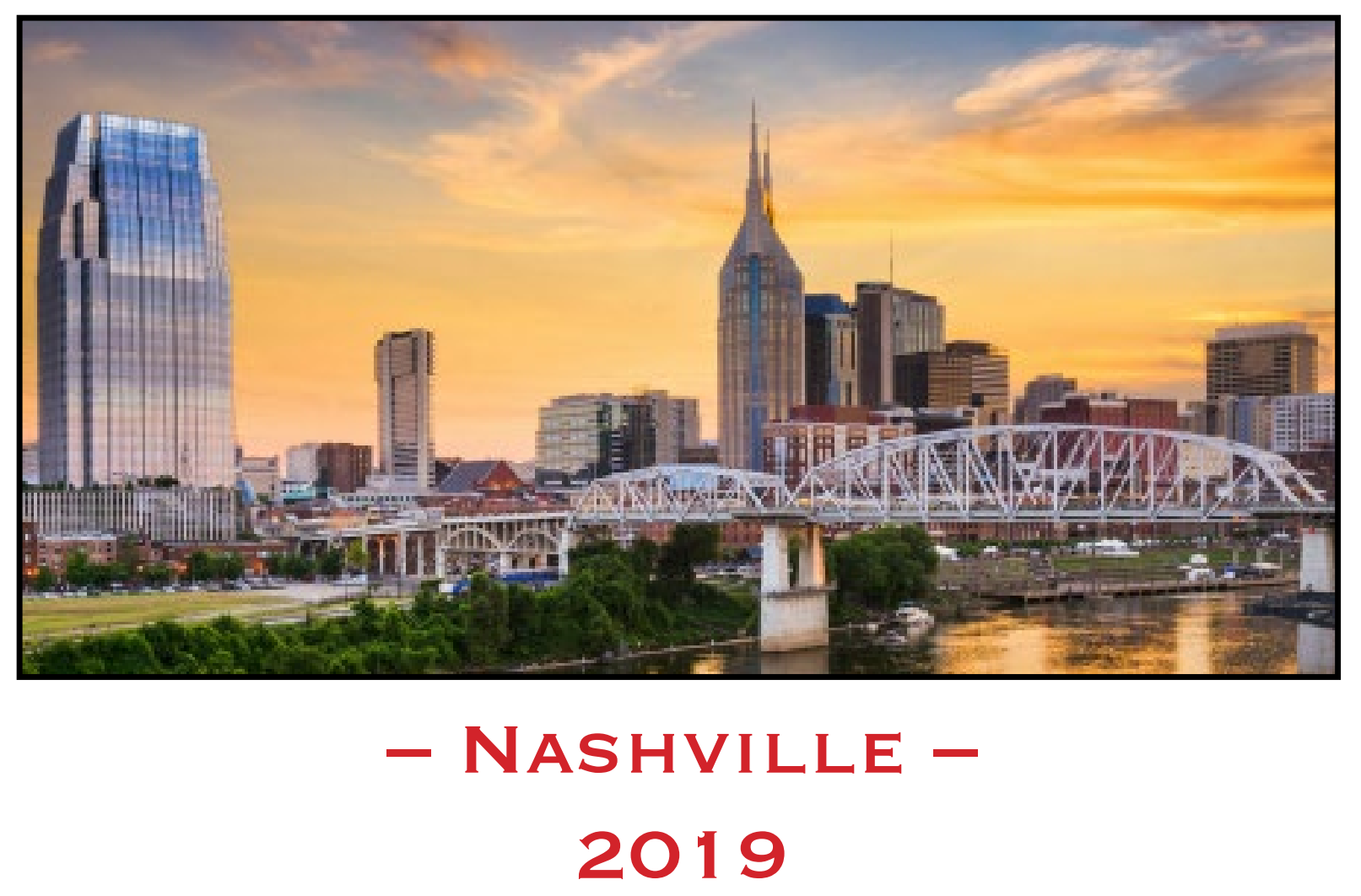

March 21 - 23, $2019 \cdot$ Belmont University - Nashville 